\title{
Reconceptualising teaching and learning in higher education: challenging neoliberal narratives of teaching excellence through collaborative observation
}

Matt O’Leary \& Vanessa Cui (Birmingham City University)

\begin{abstract}
In 2016, the introduction of the Teaching Excellence Framework (TEF) marked a watershed moment for higher education (HE) in the United Kingdom. This paper views the TEF as an extension of the neoliberal policy narrative that has dominated policy thinking and decision making in HE in recent decades. It argues that the epistemology and methodology underpinning this narrative is flawed and ill-equipped to improve the quality of teaching. As a counter narrative, this paper discusses the creation of a cycle of collaborative observation $(\mathrm{CoCO})$ between academic staff and students in an English university. Drawing on theoretical and empirical insights, the paper explores the conceptual and methodological framework behind $\mathrm{CoCO}$, as well as the preparation of academic staff and students for engaging with this collaborative approach to observation. We argue that $\mathrm{CoCO}$ offers the potential to transform understanding of learning and teaching in $\mathrm{HE}$ and the reciprocal relationship between the two.
\end{abstract}

Keywords: higher education; teaching and learning; observation; teaching excellence; collaboration

\section{Introduction}

The quality of teaching in higher education (HE) has attracted a lot of interest from governments worldwide in recent years. In the United Kingdom (UK), for example, the recent introduction of the Teaching Excellence Framework (TEF) heralds an era of 
unprecedented scrutiny and focus on the quality of teaching. With the UK government seeking to link the quality of teaching to funding, HE providers are increasingly required to demonstrate how they monitor the quality of teaching and what measures they are taking to improve it. However, current policy focus continues to promote an instrumentalist model of teaching and learning ( $\mathrm{T} \& \mathrm{~L}$ ) with teaching staff often perceived as the deliverers of knowledge and skills and students as the consumers. Furthermore, the TEF has continued the focus on monitoring and measuring the quality of teaching as a product rather than seeking to gather information that captures situated examples of the process, ultimately failing to move forward understanding of what excellent teaching might be and how best we might achieve it.

This paper is divided into two halves. The first half presents a critique of the neoliberal narrative that has dominated HE policy thinking and decision making in relation to $\mathrm{T} \& \mathrm{~L}$ in recent years. It argues that the epistemology and methodology underpinning the neoliberal policy response in $\mathrm{HE}$ is flawed and incapable of advancing our understanding of the complex interrelationships that exist between $\mathrm{T} \& \mathrm{~L}$. As a result, the impact of this policy in HE settings is that it ends up doing more of the same, creating a vicious policy circle that fails to move understanding and practice forward. As a counter narrative to this circle, the second half of the paper discusses the development of an innovative partnership between academic staff and students in a recent project, where students' inclusion is reconceptualised from passive consumer to active collaborator through the shared lens of observation. It explores the conceptual and theoretical framework of a cycle of collaborative observation (CoCO), explaining its rationale, how it differs to conventional observation approaches, along with the methodology devised to introduce and prepare staff and students for working with this approach to observation in an English university. While the project in question generated a wealth of data, it is not in the scope of this paper to explore the key findings from 
these data here as this requires a separate paper in itself. Thus this paper focuses its discussion on the conceptualisation and methodological underpinnings of the project.

\section{Neoliberal policy making in context: teaching and learning in UK higher education}

The UK HE sector has experienced a period of unprecedented reform and political intervention over the last three decades. The recent introduction of the TEF (BIS 2015) is another example of such intervention and one that has positioned the quality of teaching high on the political and policy agenda. In the lead up to the TEF, David Willetts, the former Minister of State for Universities and Science, claimed that teaching was 'by far the weakest aspect of English higher education' and was identified as being in urgent need of monitoring and improvement (Gill 2015). The current Conservative government thus created the TEF with a view to identifying, encouraging and rewarding excellence in teaching, arguing that it would act as a key lever in driving up standards across HE (BIS 2016). A key premise underpinning the government's argument was that if teaching were to be considered of equal value to research, then an equivalent scheme to the Research Excellence Framework would need to be established to enable the monitoring and measurement of the quality of teaching across higher education institutions (HEIs). Continuing its adherence to neoliberal policy making, the government decided that for the TEF to achieve its desired outcomes, it was important to create the conditions for free market competition amongst providers, which would, in the government's eyes, subsequently result in each HEI striving for excellence in teaching (O’Leary 2017).

Although reaction to the TEF has been mixed among the HE academic community to date, its introduction has undeniably provoked sector-wide debate about the status and quality of teaching. For some, the TEF heralds overdue acknowledgement of the value of teaching as 
the core business of many HEIs, especially in light of how research has traditionally featured as the main strategic priority. Yet equally the TEF has been met with a great degree of scepticism from HE academics and student bodies who view it as another example of government policy driven by a neoliberal agenda intent on exercising greater control over their work, along with the acceleration and expansion of the marketisation of the sector (e.g. French and O'Leary 2017).

The global phenomenon/ideology referred to as 'neoliberalism' provides a useful conceptual lens through which to view policy developments like the TEF. In recent years it is a term that has become ubiquitous in political and education policy debates. But what is its relevance when discussing $\mathrm{T} \& \mathrm{~L}$ in $\mathrm{HE}$ and the specific focus of this paper? These are important questions to consider if we are to understand the wider forces that influence priorities in determining policy and decision making in HE, along with helping to contextualise the conceptual and methodological framework of the project discussed in this paper as an alternative way of approaching the improvement of T \& L.

Davies (2017) defines neoliberalism as 'an attempt to replace political judgement with economic evaluation' (p. 5) and 'the rendering of the economy, state and society as explicit and quantified as possible (p. 10). Davies' definition evokes memories of the ideology of Thatcherism popularised during the 1980 s and encapsulated in a slogan that was commonly referred to at the time as the 'three E's' i.e. economy, efficiency and effectiveness, which were employed as the guiding rationale for the Conservative government's neoliberal agenda of the privatisation and marketisation of public sector institutions. As Davies alludes to in his definition of neoliberalism above, these terms were removed from the realm of political discourse and subsequently re-packaged in an ideology of so-called neutrality, which meant 
that they were conceptualised and discussed as being 'technical' rather than political or ideological issues.

In a similar vein, Ball $(2012,29)$ maintains that 'neo-liberalism involves the transformation of social relations into calculabilities and exchanges, that is into the market form, and thus the commodification of educational practice - e.g. in economies of student worth, through performance-related pay, performance management'. What Ball and Davies' explanations of neoliberalism reveal is the overriding ideological influence of the market as a conceptual lens through which to understand, organise and valorise educational practice. Every action, interaction and behaviour is one that is mediated as a market transaction with economic value that is subject to a process of quantification.

How neoliberalism operates in and on HEIs in the context of $\mathrm{T} \& \mathrm{~L}$ is through a range of what Ball refers to as 'practices and technologies' $(2012,29)$. Arguably the most recognisable of these practices in HE, itself closely aligned to the ideology of neoliberalism, is that of 'managerialism'. Like neoliberalism, managerialism is underpinned by an allegiance to the ideals of the free market and the imperatives of efficiency, calculability, control and accountability with a reliance on quantitative methods. Wallace and Hoyle (2005, 9) state that:

[Managerialism] is underpinned by an ideology which assumes that all aspects of organisational life can and should be controlled. In other words, that ambiguity can and should be radically reduced or eliminated. 
As Wallace and Hoyle's explanation of managerialism makes clear, the work of HEIs is something that can and should be systematically controlled, largely by 'a commitment to the explicitness and transparency of quantitative indicators' (Davies 2017, 6). But when it comes to $\mathrm{T} \& \mathrm{~L}$, this is problematic on two levels. First, it presupposes that the processes and outcomes of $\mathrm{T} \& \mathrm{~L}$ are controllable and measurable and that they can be controlled and measured in a consistently reliable way in the same way that phenomena in the natural world can. Secondly, it undermines the importance and role of professional judgement or what Hargreaves and Fullan (2012) refer to as 'professional capital' in making sense of these complex processes. These are both significant issues that will be explored in more depth below but first let us conclude our discussion of managerialism.

Typical examples of managerialism that have become firmly entrenched in HEIs in the UK include performance management and quality assurance systems such as appraisals or performance reviews, target setting, course audits, monitoring of student progression and attainment, workload allocation models etc. These are all examples of a form of metagovernance (Ball 2012). In other words, different means of governing or controlling what HEIs and their staff do by establishing and organising the conditions for governing the quality of those activities. But managerialism is arguably one of three interrelated levers responsible for generating these 'conditions' of metagovernance that co-exist, the other two of which are performativity and marketisation.

Ball $(2003,215)$ has described performativity as a culture that 'requires individual practitioners to organise themselves as a response to targets, indicators and evaluations, to set aside personal beliefs and commitments and live an existence of calculation'. In short, performativity 'operates within a framework of judgement' (Ball 2012, 31) and is concerned 
with measuring and evaluating quality, productivity and performance. Two situated examples of this in HE in England at an institutional and individual level would be the TEF and performance-based models of observations of staff teaching.

Neoliberal approaches to measuring and evaluating teaching quality and its impact on student learning continue to be reliant on the use of reductive metrics to inform policy decision making and direction. But we would argue that such approaches are fundamentally flawed as they fail to capture and reflect the complexity of HE T \& L. The reasons for this relate directly to the epistemology, methodology and axiology underpinning neoliberalism. The reductionist nature of the tools used to examine and evaluate $\mathrm{T} \& \mathrm{~L}$ means that they are ill equipped to capture its complexity, thus rendering them inadequate and unsuitable means of advancing extant knowledge and understanding. In contrast, qualitative approaches like the one we discuss below are better suited to harnessing this complexity. Equally, the failure to fully understand the phenomenon under investigation itself is a flaw. How, for example, can we talk about 'excellence' in T \& L without first defining clearly what we mean by these fundamental terms, 'teaching', 'learning' and 'excellence'?

Biesta (2017) asks whether under such a regime indicators of quality are appropriated as definitions of quality. These neoliberal approaches thus create an environment in which what is measured no longer actually represents what we really value in education. Instead, we are forced to value what is purportedly being measured. A vicious circle is thus created where policy and practice becomes stuck in a conceptual and operational rut as it ends up doing more of the same (i.e. measuring or attempting to measure $\mathrm{T} \& \mathrm{~L}$ related activity) without actually making a tangible impact on moving knowledge forward and subsequently improving T \& $\mathrm{L}$. This inevitably raises the question of how best we can break this circle, a 
key driver underpinning the project discussed below. An important starting point is to identify gaps in knowledge, in this case how we can best go about capturing situated examples of T \& L. To do so requires an appreciation of the complexity and contextual factors that shape $\mathrm{T} \& \mathrm{~L}$ in $\mathrm{HE}$, as we discuss below.

\section{Students as consumers: a marketised model of teaching and learning}

There are many different facets to the neoliberalisation of HE. But the particular aspect that we wish to discuss in this paper is the commodification of students as 'consumers', as this is directly relevant to our focus on T \& L exemplified by the project discussed below.

With current government policy choosing to frame HE explicitly in economic terms, recent policy discourse has emphasised students as customers of a commodity and/or service users, as evidenced in the White Paper with the introduction of the TEF:

Competition between providers in any market incentivises them to raise their game, offering consumers a greater choice of more innovative and better quality products and services at lower cost. Higher education is no exception ... For competition in the HE sector to deliver the best possible outcomes, students must be able to make informed choices ... Information, particularly on price and quality, is critical if the higher education market is to perform properly (BIS 2016).

The student-consumer conceptualisation and discourse plays a key part in HE marketisation and privatisation. It is underpinned by a set of interrelated suppositions where students come to see $\mathrm{HE}$ as a right based on the increasingly private nature of their contribution with the value of HE equated to the costs of participating (Tomlinson 2017). Throughout the White 
Paper and recent outputs from the Office for Students, 'value for money' is stressed as a key driver to determining quality in HE participation. Two interlinked conceptualisations of 'value' articulated in the White Paper are the economic value of the degree to the labour market, measured by graduate employment metrics, and the value of the investment made by students in their HE courses. The core metrics, which include student satisfaction evaluations, are intended to capture institutional outcomes across a range of performance criteria in order to inform prospective students, thus creating a market of differentiated 'quality'. In other words, it makes explicit the link between what students pay in and what they perceive to get out of their HE experience in return, reinforcing students' status as revenue providers, consumers and evaluators of the sector.

Viewed through the current policy lens of economisation and marketisation, teaching becomes a service and/or commodity produced for students to consume and subsequently evaluate through large-scale instruments such as the National Student Survey (NSS), which is a national survey directed at all final year undergraduate students annually in the UK to gather their 'opinions on the quality of their course' (HEFCE 2017). The NSS prescribes a list of items as key indicators of the quality of the services provided by the institution for students to evaluate their HE experience. Based on this student-consumer model and the 'value for money' ethos, such types of evaluations focus on the (in)congruence between student expectations of teaching and their perceptions of teaching on their course. Advocates of the marketisation of HE would argue that by increasing competition between HEIs for students, this forces them to prioritise improvements in the quality of teaching, as each HEI seeks to gain a market advantage over its competitors in order to attract more students. 
In a marketised system, institutions need to enhance their market competitiveness, which can often lead to the creation of institutional policies and initiatives that serve to reinforce the student-consumer ethos. An example of this at an institutional level is how the 'student voice agenda' has spawned a predominant culture of student evaluation (e.g. O'Leary, Cui and French forthcoming). From module evaluations, to end of year evaluations and the NSS, all these have become integral to institutions collecting student feedback. The quality of teaching is regarded as one of several key criteria used to determine the effectiveness of an institution's services and products in helping students achieve their desired outcomes. Implicit in these evaluations is the assumption that students are best placed to make judgements about teaching and what they want to get from HE. However, such metrics are problematic when used to inform our understanding of $\mathrm{T} \& \mathrm{~L}$ and policy decision making within institutions. Used as a quality enhancement tool to evaluate staff performance on an annual basis, the value of such evaluations is questionable in terms of their contribution to informing situated understanding of $\mathrm{T} \& \mathrm{~L}$ practices.

For some, as long as the institution provides the right environment, there is an assumption that learning will take care of itself. This position foregrounds teaching as the most critical factor in achieving desirable learning outcomes. Though 'student voice' does appear in evaluations of teaching, it is enshrined in a process model of communication (Fiske 1990) in which students' views on teaching are disseminated to staff, sometimes directly, sometimes via management and/or professional services. Students may be consulted about their perceptions of teaching with the purported aim of raising standards of teaching quality, rather than for any sense of active membership of their course community as learners. Gourlay (2015) refers to this form of student engagement as 'the tyranny of participation', where only public and observable forms of behaviours are viewed as legitimate engagement behaviour. 
In terms of learning, institutions also evaluate successful forms of learning and learning outcomes through the widespread incorporation of institutional and programme-level evaluation and performance data, through student attainment, progression and retention (Ransome 2011). Macfarlane (2015) calls this a form of 'student performativity' and questions its intrinsic educational value. Green (2011) has also critiqued such student metrics, questioning how much they meaningfully enhance situated understanding of T \& $\mathrm{L}$ and/or bring about subsequent improvements.

A recent study by Tomlinson (2017) involving 68 undergraduate students from across seven UK HEIs engaged directly with students' perceptions of the 'student-consumer' and how students approached HE in this policy context. The study revealed that students saw themselves as consumers in some ways but not all subscribed to consumerism. While some adopted a rationalistic approach to assessing the potential economic value of their learning experiences and treated their relationship with their lecturers as client-service provider, the majority considered HE participation as serving a wider range of purposes. They acknowledged that they had responsibilities as students and engagement in the learning process was integral to achieving their desired outcomes. Tomlinson's findings resonate with our understanding of student perceptions of their HE experience. But we would add that current mechanisms for capturing student voice on $\mathrm{T} \& \mathrm{~L}$ focus on consumer satisfaction of the product, rather than allowing for substantive involvement in discussions about the process and ways of improving $\mathrm{T} \& \mathrm{~L}$ in HE. We see this as a missed opportunity for extending student voice beyond that of the consumer, which is where the cycle of collaborative observation (CoCO) discussed in the second half of this paper has a valuable role to play. 
It is important to emphasise that students are conceptualised in many other ways beyond that of consumer. For example, others have written about them as 'academic apprentices' (Bourdieu and Passeron 1979) and 'critical agents' (Barnett 1997). In the context of T \& L, students simultaneously see themselves as consumers, academic apprentices, professional apprentices, 'Guinea pigs' of policy reform, critical agents and learners (Cui 2014). While some of these conceptualisations may seem contradictory and even conflicting, some align well for producing meaningful T \& L, in particular when situated learning is prioritised (ibid). This concurs with Bowden and Marton's (2004) position on putting learning foremost when conceptualising HE and developing policy and practices on teaching, which we will discuss further in the next part of this paper.

\section{Learning about teaching and learning in higher education: context and complexity}

$\mathrm{T} \& \mathrm{~L}$ are part of a complex, dynamic and interdependent relationship that comprises multiple elements (students, teachers, resources, environment etc.). They are socially situated, intellectual activities (Lave 1993). How we understand T \& L in HE requires the creation of knowledge and meaning situated in such complex contexts. As Lave's work $(1988,1993)$ demonstrates, meaning has a relational character, generated in the interaction between learners and teachers in the T \& L environment. Academics' experiences and understandings of T \& L in HE are often shaped by their disciplinary culture and practice (Neumann 2001). Although disciplinary knowledge is created through collective intellectual work, many academics' pedagogic knowledge and skills originate from their personal educational experiences.

Teaching in HE is a multifaceted notion. It can be viewed and understood through different lenses e.g. the performance, the process and the scholarship. This is also reflected in how the 
relationships between teachers, students and the T \& L orient themselves (e.g. Tubbs 2005; Su and Wood 2012). Previous research has identified traits of teaching excellence (e.g. Skelton 2004; Shephard et al 2010), the most commonly occurring of which include the complex interactions and negotiations between aspects of technical, emotional and ethical deliberations. Teaching excellence also involves consistent negotiations and simultaneous engagement between the personal, collaborative, organisational and societal needs (Wood 2017).

Today's mass participation in HE means that students are from a diverse range of socioeconomic, cultural and educational backgrounds with a wide-ranging set of needs, thus resulting in a highly complex $\mathrm{T} \& \mathrm{~L}$ environment. Besides, students bring with them their lifetime experiences of learning and their understandings of T \& L, which makes it increasingly difficult and insufficient for academic staff to rely on traditional apprenticeship approaches to developing their teaching (Knight and Trowler 2000). Furthermore, the disciplinary, acculturated perspectives and approaches academics embody provide them with a frame of reference that can often differ from many of their undergraduate students, who are yet to be part of these same academic disciplinary communities.

Over the last three decades, there has been an increase in institutional T \& L initiatives for academic staff, from the introduction of formal courses leading to recognised teaching qualifications, to informal training and support. While these initiatives and programmes provide opportunities for staff to invest in professional development and the scholarship of $\mathrm{T}$ $\&$ L, they are often driven by the needs of quality assurance systems, which perpetuate managerialist cultures and practices, the use of observation as a performance management tool being a case in point. 
Professional development programmes such as the Postgraduate Certificate in HE T \& L offer an opportunity to engage with generalised scholarly knowledge on $\mathrm{T} \& \mathrm{~L}$ and provide staff with a platform to develop understanding outside their disciplinary circle. However, much of the academic/theoretical content used in these programmes arguably lacks actionable quality when practitioners are confronted with education issues that are social/cultural in nature (Yorks, 2005). Institutional support and training is often short and periodic, which makes it difficult for staff to pursue a sustained learning opportunity of inquiry into situated T $\& \mathrm{~L}$ issues they encounter. Furthermore, despite the increasing importance of student voice in HE T \& L, there is often very limited direct involvement of students in institutional level T \& L development programmes.

As we have already argued, current policy focus continues to create an environment in which $\mathrm{T} \& \mathrm{~L}$ are largely situated and examined through the interconnected lenses of managerialism, performativity and marketisation. We maintain that a realignment of lenses is required that shifts the focus onto educational inquiry in order to understand what is really occurring in the $\mathrm{T} \& \mathrm{~L}$ environment and to bring about greater awareness of the interrelationship between the two with a view to improving practice.

In contrast to the current policy conceptualisation of students as consumers and staff as providers, we maintain that students and staff should be considered as members of their programme community who have agency and are active participants in understanding and shaping $\mathrm{T} \& \mathrm{~L}$ in their community. With this in mind, the distinction between learner voice and student voice (the student-consumer conceptualisation) must be made here. Certainly, a HE student has a number of roles within their institutions, which embodies a number of voices (e.g. see Cui 2014; Tomlinson, 2017). Learner voice, in this article, is about students 
expressing their experiences and understanding about their learning in the context of their programme; what is meaningful to them and their lecturers/academic tutors.

As Bowden and Marton (2004, 14-15) have argued, an understanding between students and staff based on a common frame of reference of $\mathrm{T} \& \mathrm{~L}$ is fundamental to building a collective consciousness of learning in the context of their programme:

Learning from other people means that we become aware of their ways of seeing things, regardless of whether or not we are convinced by, or appropriate, their ways of seeing ... this means that not only do students have to learn from teachers but teachers have to learn from students as well ... Our views of a certain phenomenon can therefore be shared or they can be complementary. Combining differing views implies richer, more powerful, ways of understanding a phenomenon or a situation and is likely to offer more options for handling varying conditions.

Viewing subject specialist learning through the eyes of others enables us to develop a mutual awareness and understanding, which in turn helps us to appreciate, challenge and further our individual and collective understandings. T \& $\mathrm{L}$ are social practices that require the key agents to engage in a process of reflexivity. Examining our own understandings and experience of $\mathrm{T} \& \mathrm{~L}$ by cross referencing these assumptions and opening them up to dialogic exchange enables us to become aware of the strengths and areas for development in our practices. Instead of disseminating feedback to each other about $\mathrm{T} \& \mathrm{~L}$, we argue that by creating shared spaces in which learners and teachers can engage in reflexive dialogue, this leads to collective sense making and meaning (Fielding 2004), as exemplified by the approach we discuss below. 


\section{Improving teaching and learning through collaborative observation}

Improving teaching and learning through collaborative observation was an 18-month

HEFCE-funded project undertaken at Birmingham City University from 2016 to 2018. It was a faculty-wide project that comprised five case studies from a range of undergraduate education and health programmes, with each case study including two academic staff and two student participants. The five case studies included: 1) Early Childhood Studies; 2) Primary Education; 3) Radiotherapy; 4) Child Nursing and 5) Adult Nursing. The project was underpinned by the ethos that improving student learning requires students and teachers to develop an awareness and understanding of learning collaboratively in the context of their respective programmes of study. In the context of programme level T \& $\mathrm{L}$, the project used the shared classroom experience as a central reference point, with students and teachers coming together to identify and discuss the critical aspects and reciprocally reflect on their understanding of these experiences. In this second half of the paper, we present the conceptualisation of the methodology and methods of our cycle of collaborative observation $(\mathrm{CoCO})$. Each of the project's five case studies undertook two cycles of observation from January 2017 to March 2018.

Classroom observation has long occupied a prominent place in the formal training, assessment and development of teachers and lecturers in schools and colleges in England. In recent years though, its application has come to be viewed quite narrowly by policy makers, inspectors and employers as an assessment tool for monitoring and measuring teacher performance (e.g. O'Leary and Brooks 2014). In contrast, its use in HE has traditionally been less commonplace, with practice much less developed across the sector. Peer-based models of observation have largely accounted for much of the engagement among HE staff, though this has varied markedly within and across institutions (e.g. Hendry and Oliver 2012; Sachs 
and Parsell 2014). However, with teaching excellence now firmly on the policy agenda in $\mathrm{HE}$, observation is increasingly becoming employed as a quality assurance tool to gather information on teaching standards within and across programmes and to evidence individual staff performance (O’Leary, Cui and French forthcoming).

Recent research studies in the field of observation have revealed that assessment-based models of observation that seek to measure teaching performance can often be a deterrent to developing innovations in practice and lead to counterproductive consequences (e.g. O'Leary and Wood 2017; O’Leary 2016). For example, findings from a large-scale study carried out in the further education sector in England revealed that teachers regarded high-stakes, performance management models of observation as of little relevance to their professional needs. There was a consensus that such models of observation failed to improve their practice and that they only existed to provide senior managers and external agencies with quantifiable data that could be used to exercise managerial control over their work. In contrast, the overwhelming majority of the study's participants agreed that low-stakes, peer-based models of observation were most conducive to sustainable change and professional learning and thus should be at the forefront of most providers' use of observation and wider professional development strategy (UCU 2013).

Drawing on the latest research and practice in the field of observation and learning from the pitfalls of how it has been misappropriated as a performance management tool, the conceptual and methodological framework of our project design started with us reconceptualising and reconfiguring the way in which we planned for the project's participants to engage with observation as a method for studying and enhancing T \& L. Severing the umbilical link between observation and its use as a method of assessing teaching 
and teacher performance was central to this process, as we were convinced that unless we were able to remove observation from the assessment context, this would jeopardise our efforts to capture situated examples of authentic teaching and learning and in turn to create a safe, trusting and collaborative environment for reflection and dialogue between staff and students. Similarly, when it came to student involvement, our approach put student voice and their active involvement in informing and shaping $\mathrm{T} \& \mathrm{~L}$ at the heart of this innovation.

CoCO (Figure 1) is underpinned by Brookfield's (1995) idea of the critically reflective practitioner. In order to challenge the hegemonic assumptions that we hold about T \& $\mathrm{L}$, Brookfield argues that it is important to draw on both our students' and our colleagues' perspectives to illuminate different interpretations of our actions and provide different frames of references to understand them. Student learning is one of four key lenses through which teachers are encouraged to evaluate the effectiveness of their teaching according to Brookfield (1995). In our model, students and staff all take an active role in critically reflecting on their practices, viewing the 'same' classroom experience from their perspective and exchanging their observations and reflections with each other. Our methodology draws individual perspectives together to observe $\mathrm{T} \& \mathrm{~L}$ at a programme-specific level rather than focusing attention on an individual's practice or a one-off session. Central to our philosophy of improving $\mathrm{T} \& \mathrm{~L}$ is the need for students and teaching staff to take shared responsibility for developing mutual understanding, using a shared frame of reference from which to generate new understandings of situated T \& L situations.

The key driver for each of the project's five case studies was to provide a platform for adopting a collaborative, inquiry-based approach for students and staff to co-investigate cognate issues relating to their respective programmes. Bowden and Marton's (2004) 
'collective consciousness' is a helpful concept to consider the learning that takes places for individuals and for the case study as a collective. This concept shares the critical social constructivist stand we adopt, emphasising how T \& L should be built on an ethos that challenges our taken-for-granted views and practices in order to develop new understandings and subsequently make improvements to T \& L.

$<$ Insert Figure 1>

CoCO began with two separate training sessions for staff and students, each session lasting five hours in total. Staff training focused on their previous experience of observations, developing an understanding of the project's collaborative approach and discussing the stages of CoCO. They worked collaboratively on a range of immersive exercises to facilitate their familiarisation with the methodology and the activities involved. For example, they practised carrying out non-judgemental observations via a selection of video clips of classroom practice and compared their observation notes and reflections with their peers. This was to help to develop an awareness of what different observers notice when they observe, reflect on their T \& L values and how these values inform their observations and reflections. While there were many similarities with the student observer training, there was a shift in focus insomuch as the students' session was concerned with helping them to think about their position as students through the lens of learning, to reflect on how they engaged with $\mathrm{T} \& \mathrm{~L}$ and how that connected to their knowledge as a whole, as well as their experience as a student on their programme.

Stage 1 of the cycle involved staff and students working with a set of prompts to compile individual reflective accounts of their learning/teaching autobiographies. Students were 
prompted to reflect on their prior experiences of learning and how they went about making sense of their experience as learners on their programmes. Staff were prompted to reflect on their T \& L journeys by focusing on what their philosophies of teaching were, how these impacted on the preparation, delivery and evaluation of $\mathrm{T} \& \mathrm{~L}$, how these connected to their philosophies of learning, and what they considered to be the relationship between $\mathrm{T} \& \mathrm{~L}$ on their respective programmes.

Stage 2 Pre-observation meetings, students and staff first met in their peer groups to discuss their individual reflections from Stage 1 and worked together on developing their learning objectives and inquiries for their case study. Aligned with our conceptualisation of learning, we adopted the term 'coaching' and underpinned this with Bokeno's (2009) work, who suggests that organisations focus on 'learning relationships', which are based upon an ethos of inquiry and a willingness to explore unasked questions. Using a coaching ethos and techniques, members in each peer group facilitated each other's development through the use of open and thought-provoking questions. The use of questions aimed to create a working ethos of enquiry and support participants in taking responsibility for their own learning. After peer discussion, staff and students came together to share and discuss their individual reflections and to connect these reflections with $\mathrm{T} \& \mathrm{~L}$ on their programme collectively. They identified the inquiries they wished to investigate together, agreed the focus and dates of the observed sessions, the roles of each member during the course of the cycle and the expectations of both parties. The focus of the discussion was on T \& L rather than the teachers/students. This was where, for the first time during CoCO, the two sets of lenses came together to co-interrogate $\mathrm{T} \& \mathrm{~L}$ on their programme.

The observation (Stage 3) involved students working in pairs to observe part of the session 
from their perspective as learners. A lecturer led the session while the other observed the $\mathrm{T} \&$ L. Students and staff agreed their focus prior to the observations. To ensure that they were able to carry out high quality observations with limited distractions to their learning during the session, it was recommended that each individual student limit their observation time to 30 minutes. Observers took handwritten notes with no prescribed criteria on what to observe. Following the observation, immediate reflections (Stage 4) were carried out by all participants individually. Each observer then developed their notes, supplementing them with questions and comments in preparation for their post-observation meetings.

Stage 5 post-observation meetings took a similar format to stage 2 . Students and staff met in their peer groups to discuss their observation experience and relate what they had observed to their own learning/teaching experience on the programme. When meeting as a group, all participants brought their notes and reflections to the discussion and linked these back to the stage 2 discussion and the agreed learning objectives and focus. Each individual's perspective came together to form a collective understanding of the shared classroom $\mathrm{T} \& \mathrm{~L}$ they had observed and experienced.

Stage 6 of the cycle culminated in a reflective write up by each participant independently. The aim was to capture the holistic experience of both parties of the cycle. What's more, each participant was prompted to make connections between this observation experience with their past $\mathrm{T} \& \mathrm{~L}$ experiences and their $\mathrm{T} \& \mathrm{~L}$ experiences across the programme.

\section{Ethical considerations}

Students and staff collaborating as co-observers and co-reflectors on $\mathrm{T} \& \mathrm{~L}$ requires careful consideration of the working relationship between them. Trust between the participants of 
$\mathrm{CoCO}$ is vital. In our project, the research team acted as a mediator at the beginning to facilitate dialogue and allow the participants to have time and space to develop trust. It was important for the students to recognise this was not an exercise in gathering feedback and evaluating staff performance. Instead, the conversations, observations and reflections were focused on making sense of the connections and intersections between $\mathrm{T} \& \mathrm{~L}$ on their programmes. Part of the training sessions focused on the use of non-judgemental statements and questions in conversations for developmental learning.

Staff and students involved in the project were self-selected. Participation was voluntary with the option to withdraw at any time. It was important for us to ensure that the participants had ownership of the work and selected the focus in their respective case studies. This included the power to decide which aspect(s) of T \& L they wished to focus on. We were keen to avoid any prescriptive and/or one-size-fits-all approach, as these contradicted the underpinning principles of $\mathrm{CoCO}$ and could potentially jeopardise the opportunities for learning between staff and students.

The relationship between participating staff and students and the rest of the programme is a factor that requires careful thought and sensitive handling. Staff are required to communicate the project, key findings and any action as a result of the project to their colleagues and their students to ensure transparency. Students also have the responsibility to ensure their work does not compromise any member of staff or student on their programme. When reporting their observation notes, staff and students were required to keep the identities of their students/peers anonymous and focus on the $\mathrm{T} \& \mathrm{~L}$ they observed rather than the individuals. 


\section{Concluding thoughts}

In this paper, we have argued for a reconceptualisation of T \& L in HE, shifting from a performative focus to one that foregrounds the importance of collaborative, educational inquiry to understand the situated realities of T \& L. We maintain that meaningful improvements to the quality of $\mathrm{T} \& \mathrm{~L}$ in $\mathrm{HE}$ require substantive collaboration between students and staff that provide opportunities for both to generate situated, reciprocal understandings of $\mathrm{T} \& \mathrm{~L}$ in the context of their programmes. Through the shared lens of observation, we believe that $\mathrm{CoCO}$ provides a platform from which to create such opportunities and understandings, with a view to making subsequent changes that are meaningful to the contextualised learning experiences of both students and academic staff. To improve the quality of $\mathrm{T} \& \mathrm{~L}$, we therefore need to consider learning on an individual and collective level, exploring the nature of the relationship between them (Bowden and Marton 2004). To do this requires academic staff and students collaborating to develop academic learning experiences that are worthwhile and potentially transformative to both.

It is, of course, important to acknowledge that the creation and implementation of an initiative like $\mathrm{CoCO}$ is not without its challenges. The main challenge we experienced throughout the project revolved around issues of time and timetabling, where staff could be paired together with a view to observing each other, including the students, within the agreed time frames of the two observation cycles and across the 18-month period of the project. The modularisation of programmes, the complex timetables of individual staff across modules and across year groups and the heavy teaching loads of the majority of faculty academic staff meant that the possibilities for coordinating pairings were reduced. This challenge was exacerbated by the fact that as we were dealing with practice-based programmes where students spent a lot of their time outside of the university on placement, the window for 
observing taught sessions was narrow and fixed. However, the commitment of the participating staff and students, along with the flexibility of the project team in adapting to the local needs and circumstances of participants on a case by case basis, enabled us to overcome this challenge.

Under current neoliberal policy initiatives like the TEF, $\mathrm{T} \& \mathrm{~L}$ have been framed as individual success measured against set criteria based on market values (e.g. Wood 2017; French 2017). We would argue that this is counterintuitive to how good T \& L is naturally developed through long-term personal and professional learning that involves critical reflection and ongoing negotiation of meaning and understanding between those involved. This process is unique to individuals and as such requires a tailored approach. T \& $\mathrm{L}$ and their interrelationship are inherently qualitative in nature and as such require appropriate methodologies and methods to explore, interrogate and make sense of these complex phenomena. Bringing students and staff together to engage in co-observation and coreflection on their shared classroom experience enables them to see $\mathrm{T} \& \mathrm{~L}$ from their respective viewpoints and understand the connections and intersections between them. This also supports one of the most effective ways of learning, which involves collaborating with others to see different perspectives and approaches and to question our own practice and beliefs.

The current policy focus seems to direct HE towards a neoliberal, marketised model governed by a reductive, managerialist philosophy and methodology. The answer to enhancing our knowledge about and improving T \& L lies not with the continuation of a neoliberal methodology but with the pursuit of alternative approaches and methodologies, as exemplified by the project outlined in this paper. As educators responsible for delivering HE 
programmes, we would argue that we have a duty not to let such political intervention distract us from directly addressing the real issues concerning T \& L. If current approaches to HE reinforce control instead of promoting active participation and informed actions, then individual growth and societal development become circumscribed. In this paper, we have argued that students and staff are best placed to take up this challenge directly. Students' involvement in improving $\mathrm{T} \& \mathrm{~L}$ needs to move beyond a reductive conceptualisation of them as passive evaluators of the teaching quality on their programmes of study; they are active members of their programme and HE community and their interest in this community is learning. Reconceptualising them as members of the same community in the context of their programme means they have the shared goal of learning their subject/discipline individually and collectively. Without assuming students and/or staff are experts of T \& L, the best way to embark on meaningful and sustainable improvements is thus to build a shared understanding of $\mathrm{T} \& \mathrm{~L}$ between them in the context of their programme. CoCO illustrates how we can reconceptualise and reconfigure observation as a tool for supporting the genuine improvement of $\mathrm{T} \& \mathrm{~L}$.

\section{References}

Ball, S. J. 2003. 'The teacher's soul and the terrors of performativity.' Journal of Education Policy, 18(2), 215-228.

Ball, S. J. 2012. Global Education Inc. New policy networks and the neoliberal imaginary. London: Routledge.

Barnett, R. 1997. Higher education: A critical business. Buckingham: Open University. Biesta, G. 2017. 'Education, Measurement and the Professions: Reclaiming a space for democratic professionality in education.' Educational Philosophy and Theory, 49(4), 315330. 
Bokeno, R. 2009. 'Genus of learning relationships: mentoring and coaching as communicative interaction.' Development and Learning in Organizations, 23(1) 5-8.

Bourdieu, P., and J. C. Passeron. 1979. The inheritors: French students and their relation with culture. Chicago: Chicago University Press.

Bowden, J., and F. Marton. 2004. The University of Learning: beyond quality and competence, London: Routledge.

Brookfield, S. D. 1995. Becoming a critically reflective teacher. San Francisco: Jossey-Bass.

Cui, F. 2014. The 'wicked' problem of employability development in HE degree programmes: experiences, understandings and perceptions of lecturers and students, unpublished $\mathrm{PhD}$ Thesis, Liverpool John Moores University: Liverpool.

Davies, W. 2017. The Limits of Neoliberalism. London: Sage.

Department for Business, Innovation and Skills (BIS). 2016. Success as a Knowledge Economy: Teaching Excellence, Social Mobility and Student Choice, Higher Education White Paper.

Department for Business, Innovation and Skills (BIS). 2015. Fulfilling our potential: Teaching excellence, social mobility and student choice, HMSO.

Fielding, M. 2004. 'New Wave' Student Voice and the Renewal of Civic Society. London Review of Education, 2(3), 197-217.

Fiske, J. 1990. Introduction to Communication Studies. London: Routledge French, A. 2017. 'Contextualising Excellence In Higher Education Teaching: Understanding The Policy Landscape', chapter in French, A., and M. O’Leary. (eds) 2017. Teaching Excellence in Higher Education: Challenges, Changes and the Teaching Excellence Framework. Bingley: Emerald Group Publishing. 
French, A., and M. O'Leary. (eds). 2017. Teaching Excellence in Higher Education:

Challenges, Changes and the Teaching Excellence Framework. Bingley: Emerald Group Publishing.

Gill, J. 2015. David Willetts interview: 'What I did was in the interests of young people', Times Higher Education. Article published online $18^{\text {th }}$ June 2015. Available at:

https://www.timeshighereducation.com/david-willetts-what-i-did-was-in-the-interests-ofyoung-people. Accessed 04/05/2017.

Gourlay, L. 2015. “'Student Engagement' and the Tyranny of Participation.” Teaching in Higher Education, 20(4), 402-411.

Green, J. 2011. Education, Professionalism and the Quest for Accountability. New York: Routledge.

Hargreaves, A., and M. Fullan. 2012. Professional capital: transforming teaching in every school. New York: Teachers' College Press.

Hendry, G., and Oliver, G. 2012. 'Seeing is believing: the benefits of peer observation.' Higher Education Funding Council For England. 2017. National Student Survey. Last updated online $21^{\text {st }}$ December 2017. Available at: http://www.hefce.ac.uk/lt/nss/. Accessed $29 / 01 / 2018$.

Knight, P. and P. Trowler. 2000. 'Department Level Cultures and the Improvement of Learning and Teaching.' Studies in Higher Education, 25(1), 69 - 83.

Lave, J. 1988. Cognition in practice: Mind, mathematics and culture in everyday life.

Cambridge: Cambridge University Press.

Lave, J. 1993. 'The Practice of Learning'. In Chaiklin, S. and J. Lave, (eds.) Understanding Practice. Cambridge: Cambridge University Press, 3-32. 
Macfarlane, B. 2015. 'Student Performativity in Higher Education: Converting Learning as a Private Education Learning in the United Kingdom.' Higher Education Quarterly, 65(2), 206-223.

Neumann, R. 2001. 'Disciplinary differences and university teaching', Studies in Higher Education, 26, 135-146.

O’Leary, M. (Ed). 2016. Reclaiming lesson observation: supporting excellence in teacher learning. Abingdon: Routledge.

O’Leary, M. 2017. 'Monitoring and measuring teaching excellence in higher education: from contrived competition to collective collaboration', chapter in French, A., and M. O'Leary. (eds) 2017. Teaching Excellence in Higher Education: Challenges, Changes and the Teaching Excellence Framework. Bingley: Emerald Group Publishing, 75-107. O’Leary, M., and V. Brooks. 2014. 'Raising the stakes: classroom observation in further education sector in England'. Professional Development in Education, 40(4), 530-545. O’Leary, M., and P. Wood. 2017. 'Performance over professional learning and the complexity puzzle: lesson observation in England's further education sector', Professional Development in Education, Vol. 43(4), 573-591.

O’Leary, M., Cui, V., and French, M. Forthcoming in 2018. Understanding, recognising and rewarding teaching quality in higher education: an exploration of the impact and implications of the Teaching Excellence and Student Outcomes Framework, UCU Project Report.

Ransome, P. 2011. "Qualitative Pedagogy versus Instrumentalism: And Antinomies of Higher Space into a Public Performance." Higher Education Research and Development, 34(2), 338-350.

Sachs, J. and Parsell, M. (eds.) 2014. Peer Review of Learning and Teaching in Higher Education - International Perspectives. Springer Dordrecht Heidelberg: London New York. 
Shephard, K., T. Harland., S. Stein., and T. Tidswell. 2010. 'Preparing an application for a higher-education teaching-excellence award: Whose foot fits Cinderella's shoe?' Journal of Higher Education Policy and Management, 33(1), 47-56.

Skelton, A. 2004. 'Understanding teaching excellence in higher education: A critical evaluation of the national teaching fellowships scheme.' Studies in Higher Education, 29(4), 451-468.

Su, F., and M. Wood. 2012. 'What makes a good university lecturer? Students' perceptions of teaching excellence.' Journal of Applied Research in Higher Education, 4(2), 142-155. Tomlinson, M. 2017. “Student perceptions of themselves as 'consumers' of higher education." British Journal of Sociology of Education, 38(4), 450-467

Tubbs, N. 2005. Philosophy of the teacher. Oxford: Blackwell.

University and College Union (UCU). 2013. Developing a National Framework for the Effective Use of Lesson Observation in Further Education, Project Report for University and College Union, Nov 2013, Available at: http://www.ucu.org.uk/7105. Accessed 25/10/2016. Wallace, M., and E. Hoyle. 2005. Towards Effective Management of a Reformed Teaching Profession, paper presented at the 4th seminar of the ESRC Teaching and Learning Research Programme thematic seminar series 'Changing Teacher Roles, Identities and Professionalism', King's College London. [Accessed 22/09/2017]. Available at: http://www.kcl.ac.uk/content/1/c6/01/41/66/paper-wallace.pdf

Wood, P. 2017. 'From Teaching Excellence To Emergent Pedagogies: A Complex Process Alternative To Understanding The Role Of Teaching In Higher Education', chapter in French, A., and M. O'Leary. (eds) 2017. Teaching Excellence in Higher Education: Challenges, Changes and the Teaching Excellence Framework. Bingley: Emerald Group Publishing. 